\title{
The negative effect of desflurane on reproductive capacity in female rats
}

\author{
Turkler $\mathrm{C}^{1}$, Kulhan $\mathrm{M}^{1}$, Kulhan $\mathrm{NG}^{1}$, Onat $\mathrm{T}^{2}$, Yildirim $\mathrm{E}^{3}$, Kaplan $\mathrm{S}^{4}$, Suleyman $\mathrm{H}^{5}$, Dinc $\mathrm{K}^{1}$ \\ Erzincan Binali Yildirim University Faculty of Medicine, Department of Gynecology and Obstetrics, \\ Erzincan, Turkey.dr_canturkler@yahoo.com
}

\begin{abstract}
AIM: The aim of this study was to determine the effect of desflurane on reproductive capacity in female rats through a study of biochemical evaluations.

METHOD: After experimental procedure, the blood samples of female rats were collected, and the malondialdehyde, interleukin-1-beta, total glutathione and superoxide dismutase levels were measured to evaluate oxidative stress. In addition to biochemical evaluations, the reproductive performance of the experimental groups was also examined.

RESULTS: The results of our study demonstrated that in blood samples of desflurane-treated groups of rats, the parameters indicating oxidative stress and inflammation increased, and antioxidant parameters decreased $(p<0.05)$. It was also proven that repeated desflurane doses caused infertility in female rats, prolonged the gestation period and reduced the number of offspring.

CONCLUSIONS: This study showed that recurrent desflurane application can cause infertility problems through oxidative stress in female rats (Tab. 3, Fig. 1, Ref. 25). Text in PDF www.elis.sk. KEY WORDS: desflurane, infertility, oxidative stress, rat, reproductive capacity.
\end{abstract}

\section{Introduction}

Desflurane is frequently used as an inhalation anesthetic agent in both adult and pediatric patients (1). The mechanism for creating anesthesia and analgesia is still not fully understood, but Eroglu et al showed that the use of desflurane causes oxidative stress at the tissue level (2). Previous studies have shown that desflurane causes oxidative stress in various tissues such as the brain, lungs, liver and kidneys (3).

Desflurane is also used in obstetric anesthesia (4), but the effect of this anesthetic agent on the female genital system and reproductive capacity of women is not yet known. Aksoy et al stated that the reproductive capacity of female rats decreased because of oxidative stress caused by ischemia-reperfusion in rat ovaries (5).

It is known that desflurane leads to an increase in the release of reactive oxygen species (ROS) and proinflammatory cytokines (6).

${ }^{1}$ Erzincan Binali Yildirim University Faculty of Medicine, Department of Gynecology and Obstetrics, Erzincan, Turkey, ${ }^{2}$ Bozok University Faculty of Medicine, Department of Gynecology and Obstetrics, Yozgat, Turkey, ${ }^{3}$ Hitit University Faculty of Medicine, Department of Gynecology and Obstetrics, Corum, Turkey, ${ }^{4}$ Adiyaman University Faculty of Medicine, Department of Gynecology and Obstetrics, Adiyaman, Turkey, ${ }^{5}$ Erzincan Binali Yildirim University Faculty of Medicine, Department of Pharmacology, Erzincan, Turkey

Address for correspondence: C. Turkler, Menderes Mah. 127. Sok No: 7 D Blok D:4 Nar Konutlari, Demirkent/ Erzincan, Postal code: 24000, Turkey.

Phone: +90.446.2122216, Fax: +90.446.2122211 -
The release of ROS causes oxidative stress. ROS damages cellular membrane lipids and leads to the formation of malondialdehyde (MDA). Interleukin-1-beta (IL-1 $\beta$ ) is a type of proinflammatory cytokine, the level of which has been shown to increase in tissues exposed to oxidative stress. Some antioxidant enzymes such as superoxide dismutase (SOD) and total glutathione ( $\mathrm{tGSH}$ ) protect the tissues from oxidative damage. The balance between ROS and antioxidants determines the severity of oxidative stress (7).

This information suggests that desflurane may be effective in suppressing the reproductive capacity of females by causing oxidative stress. There is no study about the effect of desflurane on the reproductive capacity of females in published literature. Therefore, the aim of this study was to investigate the effect of desflurane on reproductive capacity in female rats through a series of biochemical evaluations.

\section{Materials and methods}

Animals

The recommendations of the National Institute of Health guide for the care and use of laboratory animals (NIH Publications No. 8023, revised 1978) were taken into consideration. A total of twenty-four Wistar albino female rats and four Wistar albino male rats weighing between 240 and 258 grams were randomly chosen to be used in the study. The rats were fed and housed at normal room temperature $\left(22\right.$ to $\left.24^{\circ} \mathrm{C}\right)$ prior to the test. This study was carried out in accordance with international guidelines on the ethical use of animals (Ethics Committee Date and Number: 22.11.2018-12/211). 


\section{Experimental groups}

Female rats were randomly divided into 4 groups before the experiment as follows: healthy control-1 group (HC-1; $n=6)$, desflurane-1 group (DS-1; $\mathrm{n}=6$ ), healthy control-2 group (HC-2; $\mathrm{n}=6$ ) and a desflurane-2 group (DS-2; $=6$ ). Animals in all groups were marked with numbers (1 to 6) (Fig. 1).

\section{Experimental procedure}

The desflurane used in the study was provided by Eczacibasi-Baxter (Turkey). The anesthesia gas vaporizer was calibrated before the study commenced. The anesthetic gas was adjusted according to Haelywn's recommendation with Eger and Johnson, using a minimum alveolar concentration (MAC) of $6 \%$ desflurane $(6,8)$. To perform the experiment, the anesthesia procedure was applied to DS- $1(n=6)$ and DS-2 $(n=6)$ groups in a $40 \times 40 \times 70 \mathrm{~cm}$ transparent plastic box for 2 hours. The cages allowed observation of the animals and fixed hoses were connected to the outlet of the anesthesia machine. The anesthetic gas was released into the cages with $100 \%$ oxygen. The HC-1 and HC-2 groups of animals were kept in cages with only $100 \%$ oxygen for two hours, so that no anesthetic gas was given to the $\mathrm{HC}-1$ and $\mathrm{HC}-2$ groups. Two hours after this procedure, blood samples were taken from the tail veins of the rats to be analyzed for MDA, tGSH, SOD and IL- $1 \beta$ levels in the blood serum of DS-1, DS-2, HC-1 and HC-2 groups. Then, two mature male rats were added to the DS- 1 and $\mathrm{HC}-1$ groups consisting of six female rats to allow the rats to reproduce, and the groups were kept in an appropriate laboratory environment for two months. During this period, the pregnant rats were kept in a suitable environment in separate cages. After two months, the female rats that did not get pregnant and give birth were considered infertile.

One month later, desflurane was administered to the animals in the DS-2 $(\mathrm{n}=6)$ group for the second time for two hours by the above-mentioned method. During this period, no anesthetic gas was given to the HC-2 $(n=6)$ group. The HC-2 group animals were kept in cages with only $100 \%$ oxygen for two hours. Two hours after the second application, blood samples were obtained from the tail veins of the rats to be analyzed for MDA, tGSH, SOD and IL- $1 \beta$ levels in the blood serum of the DS- 2 and HC-2 rats. Then, two mature male rats were added to the DS-2 and HC-2 group consisting of six female rats to allow them to reproduce, and they were kept in an appropriate laboratory environment for two months. During this period, the pregnant rats were kept in a suitable environment in separate cages. In two months, the female rats that did not get pregnant and give birth were considered infertile.

The blood samples of female rats were collected, and the MDA, IL-1 $\beta$, tGSH and SOD levels were measured to evaluate oxidative stress. The biochemical results were compared between the 4 groups. Also, the reproduction results obtained from the desflurane groups were compared with the healthy control groups.

\section{Biochemical analysis of the blood samples}

Serum MDA levels

The levels of serum lipid peroxidation were detected by estimating MDA (Cayman Chemical; Cat. No: 10009055; USA) using the thiobarbituric acid test through using spectrophotometric

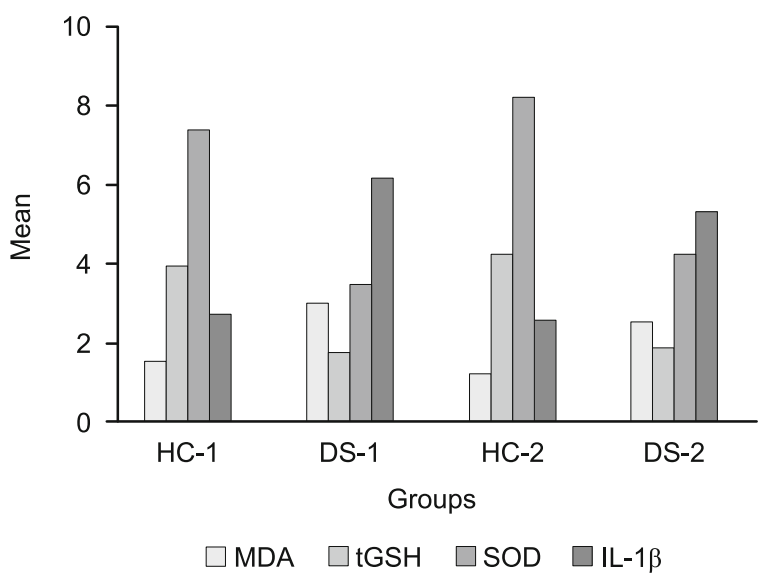

Fig. 1. MDA, tGSH, SOD, IL-1 $\beta$ levels between groups.

measurement at a wavelength of $532 \mathrm{~nm}$ according to Ohkawa et al (9). The results were expressed as micromol/mg of protein.

Serum tGSH analysis

The level of tGSH (Cayman Chemical; Cat. No: 703002; USA) in the serum was detected according to the method described by Sedlak J and Lindsay RH (10). The homogenate was used to detect GSH using 5,5'-dithiobis [2-nitrobenzoic acid]. The absorbance was measured using a spectrophotometer at a wavelength of $412 \mathrm{~nm}$. The results were expressed as nanomol/mg of protein.

Determination of SOD activity

The measurement of SOD activity (Cayman Chemical; Cat. No: 706002; USA) was performed according to the method described by Sun et al (11). SOD reacts with nitro blue tetrazolium (NBT) to produce a purple-colored formazan dye. The absorbance of the formazan was measured at a wavelength of $560 \mathrm{~nm}$ using a spectrophotometer. The results were expressed as $\mathrm{U} / \mathrm{g}$ of protein.

Serum IL- $1 \beta$ analysis

The rat IL-1 $\beta$ ELISA kit was purchased from Shanghai LZ (Cat. No: YHB0616Ra; Shanghai; China). The serum IL-1 $\beta$ levels were duly measured according to literature (12). At the end of the procedure, the absorbance was measured with a spectrophotometer at a wavelength of $450 \mathrm{~nm}$ via a microplate reader. The results were expressed as $\mathrm{pg} / \mathrm{ml}$.

\section{Statistical analysis}

SPSS software 20.0 was employed for the statistical analysis (SPSS Inc., Chicago, IL). Mean and standard deviation descriptive statistical methods were used. The differences among the four groups were evaluated by one-way ANOVA (Tukey analysis) and Kruskal-Wallis (Tamhane analysis) test. The Pearson correlation test was used to establish the relationship between variables. A p $<0.05$ level was considered statistically significant.

\section{Results}

The biochemical results of the experimental groups are shown in Table 1. As the results of the study demonstrated, there was an 
Tab. 1. Biochemical results of experimental groups.

\begin{tabular}{|c|c|c|c|}
\hline & $\mathrm{HC}-1$ & DS-1 & $\mathrm{p}$ \\
\hline MDA & $1.23 \pm 0.19$ & $2.55 \pm 0.28$ & $<0.001^{\mathrm{a}}$ \\
\hline tGSH & $4.25 \pm 0.42$ & $1.88 \pm 0.32$ & $<0.001^{\mathrm{a}}$ \\
\hline SOD & $8.21 \pm 0.51$ & $4.26 \pm 0.35$ & $<0.001^{\mathrm{a}}$ \\
\hline \multirow[t]{2}{*}{ IL-1 $\beta$} & $2.58 \pm 0.37$ & $5.33 \pm 0.54$ & $<0.001^{\mathrm{a}}$ \\
\hline & HC-2 & DS-2 & \\
\hline $\mathrm{MDA}$ & $1.83 \pm 0.25$ & $7.30 \pm 0.74$ & $<0.001^{\mathrm{a}}$ \\
\hline tGSH & $4.60 \pm 0.35$ & $1.00 \pm 0.12$ & $<0.001^{\mathrm{a}}$ \\
\hline SOD & $8.65 \pm 0.75$ & $1.61 \pm 0.23$ & $<0.001^{\mathrm{a}}$ \\
\hline \multirow[t]{2}{*}{ IL-1 $\beta$} & $1.91 \pm 0.26$ & $9.70 \pm 0.67$ & $<0.001^{\mathrm{a}}$ \\
\hline & DS-1 & DS-2 & \\
\hline MDA & $2.55 \pm 0.28$ & $7.30 \pm 0.74$ & $<0.001^{b}$ \\
\hline tGSH & $1.88 \pm 0.32$ & $1.00 \pm 0.12$ & $<0.001^{\mathrm{b}}$ \\
\hline SOD & $4.26 \pm 0.35$ & $1.61 \pm 0.23$ & $<0.001^{\mathrm{b}}$ \\
\hline IL-1 $\beta$ & $5.33 \pm 0.54$ & $9.70 \pm 0.67$ & $<0.001^{\mathrm{b}}$ \\
\hline
\end{tabular}

a: Student's t-test, ${ }^{\text {b: }}$ Paired sample t-test

increase in the levels of MDA and IL-1 $\beta$ in the serum of animals administered with desflurane, while tGSH and SOD decreased. The MDA and IL- $1 \beta$ levels in the HC- 1 and HC-2 groups were lower than in the DS-1 and DS-2 groups $(\mathrm{p}<0.05)$. On the other hand, desflurane caused a significant decrease in tGSH and SOD levels in the serum of rats when compared to those in $\mathrm{HC}-1$ and HC-2 groups $(p<0.05)$. When the biochemical results of DS-1 and DS-2 groups were compared, the MDA and IL-1 $\beta$ levels in the DS-2 group increased more than in the DS-1 group, whereas tGSH and SOD significantly decreased. Also, it was statistically proven that in the groups treated with desflurane, the parameters indicating oxidative stress and inflammation (MDA, IL$1 \beta$ ) increased, while the antioxidant parameters (tGSH, SOD) decreased.

The reproduction results of the experimental groups are statistically summarized in Table 2 . There were no infertile rats in the HC-1 and HC-2 groups, and the mean gestational periods were similar. A total of 56 offspring, 19 males and 37 females, were produced by rats in the HC-1 group, and a total of 58 offspring, 21 males and 37 females, were produced by rats in the HC-2 group. There was one infertile rat in the DS-1 group, and the mean gestational period was longer than the in HC-1 and HC-2 groups. A total of 32 offspring, 19 male and 13 females, were produced by the DS-1 group. There were three infertile rats in the DS-2 group, and the mean gestational period was longer than in $\mathrm{HC}-1, \mathrm{HC}-2$ and DS-1 groups. A total of 12 offspring, 10 male and 2 females, were produced by rats in this DS-2 group. When examining the average number of offspring, there were 9.3, 9.6, 6.4, and 4 in HC1, HC-2, DS-1 and DS-2 groups, respectively. The average number of offspring in the DS-1 and DS-2 groups was lower than in the other two groups and the differences were statistically significant $(p<0.05)$. The correlation of reproductive results according to the biochemical data of experimental groups treated with desflurane are summarized in Table 3.

\section{Discussion}

Desflurane is a volatile anesthetic gas that has previously been known for its cytotoxic effect. Despite its toxic effects at the cell level, it is one of the indispensable agents of anesthesia (13). Some clinical studies have shown that desflurane causes tissue damage as a result of ROS and oxidative stress $(14,15)$. Lee et al demonstrated that ROS disrupts cell function and gene structure by causing lipid-protein degradation and creating nucleic acid damage (16). Although desflurane's hepatotoxic, neurotoxic, nephrotoxic and pulmonary toxic properties are known, it is still preferred in obstetric anesthesia (17). Also, Souza et al declared that anesthetic gases like desflurane caused genomic instability, cytotoxicity and proliferative changes at the cell level (18). However, no studies about the effect of desflurane on the female genital system and reproductive capacity have been found in published literature.

Tab. 2. Reproduction results of experimental groups.

\begin{tabular}{lcccc}
\hline & HC-1 & DS-1 & HC-2 & DS-2 \\
\hline Gestation period (day) & $30.50 \pm 1.37$ & $32.40 \pm 3.20$ & $29.83 \pm 2.48$ & $50.66 \pm 2.08$ \\
Number of offspring & $9.33 \pm 1.21$ & $5.33 \pm 3.01$ & $9.66 \pm 1.36$ & $2.00 \pm 2.28$ \\
Number of male offspring & $3.16 \pm 0.75$ & $3.16 \pm 1.72$ & $3.5 \pm 0.54$ & $1.66 \pm 1.86$ \\
Number of female offspring & $6.16 \pm 1.60$ & $2.66 \pm 2.16$ & $6.16 \pm 1.32$ & $0.33 \pm 2.89$ \\
Male/Female offspring ratio & $0.56 \pm 0.26$ & $1.68 \pm 1.63$ & $0.59 \pm 0.21$ & $0.118^{\mathrm{b}}$ \\
\hline
\end{tabular}

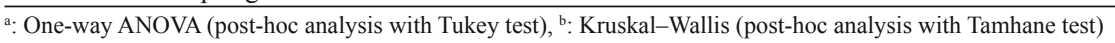

Tab. 3. The correlation of reproductive results according to the biochemical data for experimental groups treated with desflurane.

\begin{tabular}{|c|c|c|c|c|c|c|c|c|c|c|}
\hline & \multicolumn{2}{|c|}{ Gestation period (day) } & \multicolumn{2}{|c|}{ Number of offspring } & \multicolumn{2}{|c|}{$\begin{array}{c}\text { Number of male } \\
\text { offspring }\end{array}$} & \multicolumn{2}{|c|}{$\begin{array}{c}\text { Number of female } \\
\text { offspring }\end{array}$} & \multicolumn{2}{|c|}{$\begin{array}{l}\text { Male/Female offspring } \\
\text { ratio }\end{array}$} \\
\hline & $\mathrm{r}$ & $\mathrm{p}$ & $\mathrm{r}$ & $\mathrm{p}$ & $\mathrm{r}$ & $p$ & $\mathrm{r}$ & $\mathrm{p}$ & $\mathrm{r}$ & $\mathrm{p}$ \\
\hline MDA (DS-1) & 0.361 & 0.118 & -0.674 & $<0.001$ & -0.370 & 0.075 & -0.640 & 0.001 & 0.275 & 0.254 \\
\hline tGSH (DS-1) & -0.538 & 0.015 & 0.789 & $<0.001$ & 0.361 & 0.083 & 0.806 & $<0.001$ & -0.696 & 0.001 \\
\hline SOD (DS-1) & -0.495 & 0.026 & 0.726 & $<0.001$ & 0.273 & 0.197 & 0.748 & $<0.001$ & -0.624 & 0.004 \\
\hline IL-1 $\beta$ (DS-1) & 0.502 & 0.024 & -0.697 & $<0.001$ & -0.244 & 0.251 & -0.727 & $<0.001$ & 0.583 & 0.009 \\
\hline MDA (DS-2) & 0.976 & $<0.001$ & -0.948 & $<0.001$ & -0.712 & 0.009 & -0.940 & $<0.001$ & 0.934 & 0.001 \\
\hline tGSH (DS-2) & -0.973 & $<0.001$ & 0.908 & $<0.001$ & 0.604 & 0.038 & 0.940 & $<0.001$ & -0.957 & $<0.001$ \\
\hline SOD (DS-2) & -0.971 & $<0.001$ & 0.904 & $<0.001$ & 0.596 & 0.041 & 0.939 & $<0.001$ & -0.962 & $<0.001$ \\
\hline IL-1 $\beta$ (DS-2) & 0.962 & $<0.001$ & -0.945 & $<0.001$ & -0.660 & 0.020 & -0.962 & $<0.001$ & 0.968 & $<0.001$ \\
\hline
\end{tabular}


Erbas et al declared that desflurane increased the total oxidants level in the post-operative period compared to the levels before the operation (14). This information shows that tissue damage caused by desflurane due to oxidative stress can be prolonged.

When published literature is examined, it is seen that MDA and IL-1 $\beta$ increases in the experimental groups treated with desflurane, while SOD and tGSH decreases $(3,6,19,20)$. When the biochemical parameters were examined in this study, the increase in MDA and IL- $1 \beta$ in the DS- 2 group was higher than in the DS- 1 group. When SOD and tGSH were examined, it was lower than in the DS-1 group. This outcome suggested that repeated desflurane application increases the level of oxidative stress and inflammation.

In addition, desflurane has been shown to induce the apoptosis mechanism, especially in neuron cells, and causes accelerated cell death. Cysteine-containing aspartate-specific proteases 3 (Caspase 3 ) and the nuclear factor-kappaB (NF-kappaB)-dependent apoptosis pathway has a very important role in the death of neurons (12, $21,22)$. NF-kappaB is an important regulator of genes that control apoptosis. Zhao et al stated that the expression of NF-kappaB was decreased in hippocampal neurons treated with desflurane. This causes apoptosis of hippocampal neurons, and the neuron cells die. In a study on bovine ovaries, Valdez et al hypothesized that the activation of NF-kappaB inhibits apoptosis in granulosa cells of dominant follicles (23). They showed that the increases of NF-kappaB activity in ovarian tissue decreases the apoptosis of granulosa cells. When the reproduction results of the DS-1 group was examined in our study, it was determined that the duration of pregnancy was prolonged and the number of offspring obtained was reduced. This situation was more apparent in the DS-2 group. It can be suggested that the recurrent application of desflurane in our study caused an exacerbation of oxidative stress in uterine and ovarian tissues, thus affecting the reproduction capacity in rats from DS-1 and DS-2 groups. The decrease in the number of offspring obtained in the experimental groups treated with desflurane can be explained by the decline in NF-kappaB activity and number of dominant follicles in the ovarian tissue.

When the gender ratios of offspring in the experimental groups were examined, an unexpected result was seen. The female gender was dominant in the offspring obtained from the HC-1 and HC-2 groups, but this ratio was reversed in the DS-1 and DS-2 groups. Some researchers found that the number of male offspring increased due to the oxidative stress on the remaining ovaries in unilaterally ovariectomized rats (5). Testosterone and its active form, dihydrotestosterone, have a major role in the development of male genital organs (24). Also, we know that the production of adrenal gland hormones increases when the mother is stressed (25). One reason for the high ratio of male/female offspring in the experimental groups receiving desflurane may lie in the oxidative stress in the mother and in the resulting increase in the androgenic hormone level. The second reason for the high ratio of male/female offspring in the experimental groups receiving desflurane may lie in the genotoxic effects of desflurane on X-chromosomes. However, there is no data indicating that the number of male offspring increased in the groups treated with desflurane in the study (Tab. $\left.2, p=0.118^{b}\right)$. This finding does not agree with published literature
(5). A decline in the number of female offspring obtained from the DS-1 and DS-2 groups was the reason for the high ratio of male/ female offspring. The main reason for the decline in the number of female offspring obtained from the DS-1 and DS-2 groups may lie in the genotoxic effect on the X-chromosome.

When the DS-1 group was examined, none of the biochemical parameters had a statistical correlation with the number of male offspring obtained. Furthermore, there was no statistical correlation between MDA, gestation period and male/female offspring ratio. However, when the DS-2 group was examined, all of the biochemical parameters had a statistical correlation with the reproductive results. Considering that MDA is the main molecule that increases under oxidative stress, it can be suggested that there is a negative effect from repeated desflurane anesthesia and increased oxidative stress level on all reproductive outcomes.

The experiment featured some limitations. Firstly, there is no data about the adverse effect of desflurane on the reproductive capacity of females in published literature. Secondly, the experiment used a single dose of desflurane (MAC: $6 \%$ ) at a maximum of two times. Future researchers should use different doses of desflurane to determine the mean effective dose for oxidant activity. Thirdly, desflurane-induced oxidative stress was demonstrated by biochemical changes. The damage in the uterine and ovarian tissue evaluated by future studies should be performed by using histopathology. Fourthly, in order to fully understand the reason for the high male/female offspring ratio in the experimental groups treated with desflurane, the offspring that result from abortions should be examined, and it is recommended that the study is repeated on a larger sample. Fifthly, the results of experimental studies on animals should not be extrapolated to humans.

When anesthetic gases such as desflurane are used in recurrent doses, they cause tissue damage and cell death through oxidative stress. If a woman undergoes this treatment at a young age and receives recurrent doses, it is apparent that she will have an infertility problem. This study showed that recurrent desflurane application can cause the infertility problem. As a result, the findings of our study should be supported with a larger sample of cases and with human studies.

\section{References}

1. Ozsoy HZ. Carbonic anhydrase enzymes: Likely targets for inhalational anesthetics. Med Hypotheses 2019; 123: 118-124.

2. Eroglu F, Yavuz L, Ceylan BG et al. New volatile anesthetic, desflurane, reduces vitamin $\mathrm{E}$ level in blood of operative patients via oxidative stress. Cell Biochem Funct 2010; 28 (3): 211-216.

3. Türkan H, Aydin A, Sayal A, Eken A, Akay C, Karahalil B. Oxidative and antioxidative effects of desflurane and sevoflurane on rat tissue in vivo. Arh Hig Rada Toksikol 2011; 62 (2): 113-119.

4. Altiparmak B, Çelebi N, Canbay Ö, Toker MK, Kiliçarslan B, Aypar Ü. Effect of magnesium sulfate on anesthesia depth, awareness incidence, and postoperative pain scores in obstetric patients. A double-blind randomized controlled trial. Saudi Med J 2018; 39 (6): 579-585.

5. Aksoy AN, Aydin F, Topdagi Yilmaz EP, Batmaz G, Suleyman B. The Effect of Controlled Reperfusion in the Prevention of Infertili- 
ty Caused by Ischemia Induced in the Contralateral Ovary in Rats with Unilateral Ovariectomy. Gynecol Obstet Invest 2015; 80 (3): 199-205.

6. Aldemir T, Turan S, Gomceli I et al. A comparison of the effects of desflurane and isoflurane on rat pulmonary parenchyme histopathology and malondialdehyde levels. J Pak Med Assoc 2012; 62 (11): $1174-1178$.

7. Turkler C, Kulhan NG, Ata N, Kiremitli T, Cimen FK, Suleyman H. The ameliorative effect of lutein on ovarian ischemia-reperfusion injury in rats. Bratisl Lek Listy 2018; 119 (11): 713-717.

8. Dikmen B, Arpaci AH, Kalayci D et al. Are there any effects of Sevoflurane and Desflurane anaesthesia on blood glucose levels in acutehyperglycemic diabetic rats? Bratisl Lek Listy 2016; 117 (6): 351-354.

9. Ohkawa H, Ohishi N, Yagi K. Assay for lipid peroxides in animal tissues by thiobarbituric acid reaction. Anal Biochem 1979; 95: 351-358.

10. Sedlak J, Lindsay RH. Estimation of total, protein-bound, and nonprotein sulfhydryl groups in tissue with Ellman's reagent. Anal Biochem 1968; 25: 192-205.

11. Sun Y, Oberley LW, Li Y. A simple method for clinical assay of superoxide dismutase. Clin Chem 1988; 34 (3): 497-500.

12. Wang L, Wang H, Duan Z, Zhang J, Zhang W. Mechanism of gastrodin in cell apoptosis in rat hippocampus tissue induced by desflurane. Exp Ther Med 2018; 15 (3): 2767-2772.

13. Onk D, Ozcelik F, Kuyrukluyildiz $\mathbf{U}$ et al. The effect of desflurane and propofol protocols on preconditioning. Adv Clin Exp Med 2017; 26 (5): 817-823.

14. Erbas M, Demiraran Y, Yildirim HA et al. Comparison of effects on the oxidant / antioxidant system of sevoflurane, desflurane and propofol infusion during general anesthesia. Rev Bras Anestesiol 2015; 65 (1): 68-72.

15. Nogueira FR, Braz LG, Souza KM et al. Comparison of DNA Damage and Oxidative Stress in Patients Anesthetized With Desflurane Associated or Not With Nitrous Oxide: A Prospective Randomized Clinical Trial. Anesth Analg 2018; 126 (4): 1198-1205.
16. Lee YM, Song BC, Yeum KJ. Impact of Volatile Anesthetics on Oxidative Stress and Inflammation. Biomed Res Int 2015; 2015: 242709.

17. Yalcin S, Aydoğan H, Yuce HH et al. Effects of sevoflurane and desflurane on oxidative stress during general anesthesia for elective cesarean section. Wien Klin Wschr 2013; 125 (15-16): 467-473.

18. Souza KM, Braz LG, Nogueira FR et al. Occupational exposure to anesthetics leads to genomic instability, cytotoxicity and proliferative changes. Mutat Res 2016; (791-792): 42-48.

19. Lin X, Ju YN, Gao W, Li DM, Guo CC. Desflurane Attenuates Ventilator-Induced Lung Injury in Rats with Acute Respiratory Distress Syndrome. Biomed Res Int 2018; 2018: 7507314.

20. Arslan A, Kuyrukluyildiz U, Binici $O$ et al. Can thiamine pyrophosphate prevent desflurane induced hepatotoxicity in rats? Acta Cir Bras 2016; 31 (3): 168-175.

21. Kodama M, Satoh Y, Otsubo $Y$ et al. Neonatal desflurane exposure induces more robust neuroapoptosis than do isoflurane and sevoflurane and impairs working memory. Anesthesiology 2011; 115 (5): 979-991.

22. Zhao H, Bu M, Li B, Zhang Y. Lipoic acid inhibited desflurane-induced hippocampal neuronal apoptosis through Caspase3 and NF-KappaB dependent pathway. Tissue Cell 2018; 50: 37-42.

23. Valdez KE, Turzillo AM. Regulation of nuclear factor-kappaB (NFkappaB) activity and apoptosis by estradiol in bovine granulosa cells. Mol Cell Endocrinol 2005; 243 (1-2): 66-73.

24. Bao AM, Swaab DF. Sexual differentiation of the human brain: relation to gender identity,sexual orientation and neuropsychiatric disorders. Front Neuroendocrinol 2011; 32: 214-226.

25. Hines M, Brook C, Conway GS. Androgen and psychosexual development: core gender identity, sexual orientation and recalled childhood gender role behavior in women and men with congenital adrenal hyperplasia (CAH). J Sex Res 2004; 41: 75-81.

Received July 20, 2019. Accepted September 16, 2019. 